\title{
Studi Kebijakan Pengembangan Tanaman Obat di Indonesia
}

\author{
Study of Policy for the Development of Medicinal Plants in Indonesia
}

\author{
Selma Siahaan* dan Ni Ketut Aryastami \\ Pusat Penelitian dan Pengembangan Humaniora dan Manajemen Kesehatan, Badan Penelitian dan \\ Pengembangan Kesehatan, Kementerian Kesehatan RI, Jl. Percetakan Negara No. 29 Jakarta, Indonesia \\ *Korenspondensi Penulis: selmasiahaan@yahoo.com
}

Submitted: 17-07-2018; Revised: 13-09-2018; Accepted: 17-09-2018

DOI: https://doi.org/10.22435/mpk.v28i3.119

\begin{abstract}
Abstrak
Indonesia kaya dengan keanekaragaman hayati. Pengobatan yang menggunakan herbal atau tanaman obat (TO) oleh masyarakat merupakan upaya masyarakat untuk hidup sehat secara mandiri. Oleh karena itu, seyogyanya pemerintah mendorong pengembangan TO yang berada pada wilayah multisektor antara lain: sektor kesehatan, pertanian, kehutanan, dan sektor informal. Karena itu kebijakan terkait TO seharusnya dapat diimplementasikan secara koordinatif, sehingga program pengembangan TO dapat bejalan baik. Studi kebijakan pengembangan TO yang dilaksanakan tahun 2013 bertujuan untuk menganalisis kebijakan dan koordinasi lintas sektor program pengembangan TO. Studi ini merupakan studi kualitatif yang informasinya diperoleh dari pengelola dan pelaksana kebijakan terkait TO pada sektor kesehatan, pertanian, kehutanan, pemerintahan pusat dan daerah, pengurus PKK, badan penelitian, dan universitas. Studi dilakukan di Jakarta, Jawa Barat, Jawa Tengah, dan Yogyakarta. Hasil studi memperlihatkan kebijakan terkait pengembangan TO di masing-masing sektor memiliki tingkat prioritas yang berbeda-beda. Kebijakan pusat di sektor kesehatan lebih mengarah bagaimana pengobatan dengan TO bisa berintegrasi dengan pelayanan kesehatan formal dan swamedikasi, sementara sektor pertanian dan kehutanan mengarah kepada industrialisasi untuk meningkatkan taraf ekonomi masyarakat. Pada tingkat daerah, pengembangan TO masih mengharapkan dukungan dari pusat terutama untuk anggaran dan pembinaan. Hasil analisis menunjukkan masih ada gap antara kebijakan dengan pelaksanaan pengembangan TO. Secara umum, koordinasi masih menjadi kelemahan setiap sektor, baik koordinasi lintas sektor maupun koordinasi dari pusat ke daerah. Program-program yang sudah baik di tingkat pusat menjadi kurang berarti karena kurangnya sosialisasi dan pelaksanaan di lapangan. Diperlukan adanya kebijakan terobosan untuk peningkatan pemanfaatan TO baik untuk kesehatan maupun peningkatan ekonomi.
\end{abstract}

Kata kunci: tanaman obat; kebijakan; lintas sektor; swamedikasi

\begin{abstract}
Indonesia is rich in biodiversity. The treatment that uses herbs or medicinal plants (MP) by the community is an effort of the community to live a healthy life independently. Therefore, the Government should encourage the development of MP in the multi-sector areas, among others: health, agriculture, forestry and the informal sector, therefore policies related to MP should be implemented coordinatively, so that the MP development program can run well. The policy for the development of the MP study carried out in 2013 was aimed at analyzing policies and coordination across sectors of the MP development program. It is a qualitative study whose information is obtained from managers and implementers of policies related to MP in the health sector, agriculture, forestry, central \& regional government, PKK administrators, research bodies and universities. The study was conducted in Jakarta, West Java, Central Java and Yogyakarta. The study results show that policies related to the development of MP in each sector have different priority levels. The central policy in the health sector is more directed at how treatment with MP can integrate with formal health services and self-medication, while the agricultural and forestry sectors lead to industrialization to improve the economic level of the community. At the regional level, the development of MP still expects
\end{abstract}


central support, especially for budgets and coaching. The analysis shows that there is still a gap between policies and the implementation of MP development. In general, coordination is still a weakness for each sector, both cross-sectoral coordination and coordination from the center to the regions. Programs that have been good at the central level have become less meaningful because of the lack of socialization and implementation in the field. The need for breakthrough policies to increase the utilization of MP for both health and economic improvement.

Keywords: medicinal plants; policy; cross-sector; self-medication

\section{PENDAHULUAN}

World Health Organization (WHO) melalui World Health Assembly tahun 2014 merekomendasikan penggunaan obat tradisional (OT) untuk pencegahan dan pengobatan penyakit kronis, degeneratif, dan kanker. Menurut WHO pengobatan tradisional termasuk herbal medicine telah digunakan secara terus menerus oleh setiap negara di dunia. Akan tetapi pengobatan menggunakan obat tradisional harus digunakan secara rasional dan berbasis bukti. ${ }^{1}$ Di negara berkembang pengguna pengobatan tradisional ini mencapai lebih dari $80 \%$ dari jumlah populasinya. ${ }^{2,3}$ Di Indonesia, pemerintah menyatakan bahwa penggunaan pengobatan tradisional dengan jalan mengonsumsi obat herbal dan jamu atau obat-obat lainnya yang berasal dari tanaman obat (TO) dapat mendorong kemandirian masyarakat hidup sehat. ${ }^{4}$ Pengobatan tersebut harus aman dan bermanfaat baik secara tersendiri maupun terpadu dalam pelayanan kesehatan. Kebijakan terakhir yang dikeluarkan oleh pemerintah adalah Keputusan Menteri Kesehatan Republik Indonesia Nomor Hk.01.07/Menkes/187/2017 tentang Formularium Ramuan Obat Tradisional Indonesia yang berisi "informasi tentang jenis-jenis tumbuhan obat yang tumbuh di Indonesia yang telah terbukti aman jika digunakan sesuai aturan dan secara empiris bermanfaat bagi kesehatan".

Indonesia memiliki $30.000 \mathrm{TO}$, sekitar 7.000 berkhasiat sebagai obat, tetapi baru 20\% yang telah dieksplorasi. ${ }^{4}$ Menurut Komala et $\mathrm{al}^{5}$ biofarmaka kurang berkembang di Indonesia, antara lain disebabkan masih kurangnya pengetahuan masyarakat terhadap khasiat dan cara penggunaan TO. Masyarakat memiliki pengetahuan yang terbatas mengenai berbagai obat herbal dan khasiatnya. ${ }^{6}$ Hasil penelitian Badan Litbang Kesehatan tahun 2011 menunjukkan bahwa masyarakat yang setia menggunakan TO sebagai obat tradisional untuk menjaga kesehatan sebagian besar berusia 50 tahun ke atas, sedangkan orang muda lebih suka menggunakan obat modern yang lebih praktis. ${ }^{7}$ Selain itu, masih terbatas TO yang terstandardisasi yang diperlukan untuk menjaga mutu dan keamanan penggunaan TO sebagai obat. ${ }^{8}$ Penyebab lain adalah petani dan pelaku usaha kurang memahami kebutuhan pasar domestik dan ekspor yang menginginkan produk siap pakai yang telah diolah. ${ }^{9,10}$ Lebih jauh lagi fasilitas kesehatan formal seperti rumah sakit, puskesmas, klinik, dan praktek pribadi terkesan masih enggan menggunakan obat tradisional dalam memberikan pelayanan kesehatan kepada pasien. ${ }^{11,12}$

Kebijakan Obat Tradisional Nasional (Kontranas) melalui SK No.381/Menkes/SK/ III/2007 telah merumuskan permasalahan terkait TO sebagai obat tradisional dan memberikan pedoman bagi pengembangan TO. Tetapi kebijakan tersebut belum dikuti dengan implementasi yang mendorong pengembangan $\mathrm{TO}$ tersebut. Hal ini dapat disebabkan kebijakan obat tradisional belum diikuti program yang terkonsep dan alokasi anggaran yang jelas, baik untuk sektor kesehatan maupun sektor lain, serta kurangnya koordinasi yang jelas dan terpadu antar sektor terkait mengenai program-program pengembangan $\mathrm{TO} .{ }^{13}$

Agar TO dapat berkembang baik, hal-hal tersebut di atas harus menjadi perhatian khusus pemerintah. Untuk itu dibutuhkan sinergisme kebijakan pemerintah yang dapat mendukung koordinasi lintas sektor dan diterjemahkan melalui program-program untuk pengembangan TO. Tulisan ini bertujuan untuk menganalisis kebijakan dan koordinasi lintas sektor program TO yang ada yang diharapkan dapat menjadi masukan dalam pengembangan kebijakan pemanfaatan TO baik di sektor kesehatan maupun sektor terkait lainnya sehingga misi pemerintah untuk menyehatkan masyarakat melalui upaya kemandirian dapat dicapai.

\section{METODE}

Studi ini merupakan penelitian kualitatif eksplorasi, yaitu dengan wawancara mendalam terhadap pemegang kebijakan terkait TO di sektor kesehatan, pertanian, dan kehutanan di pusat mengenai kebijakan terkait TO, serta kelompok diskusi terarah kepada pemegang program dan stakeholders terkait mengenai pelaksanaan dan perkembangan TO di tingkat daerah (kabupaten). Wawancara mengenai kebijakan dan pelaksanaan TO dilakukan juga terhadap pakar dan akademisi TO. Hasil wawancara dan KDT dianalisis untuk menilai gap antara kebijakan dan implementasi 
kebijakan tersebut. Studi dilakukan dari bulan Mei sampai dengan Oktober 2013.

Studi dilakukan di dua kabupaten pada dua provinsi yang yang memiliki persentase penggunaan obat tradisional yang masuk kategori tertinggi berdasarkan data Riset Kesehatan Daerah (Riskesdas) 2010 yaitu Provinsi Jawa Tengah dengan kabupaten terpilih yaitu Kabupaten Karanganyar dan Provinsi Jawa Barat dengan kabupaten terpilih Kabupaten Bogor karena di kedua kabupaten tersebut banyak terdapat TO dan cukup banyak masyarakat yang memanfaatkan TO sebagai obat tradisional. ${ }^{7}$ Disamping itu studi dilakukan juga di pusat (Jakarta) yaitu di Kementerian Kesehatan, Kementerian Pertanian, Kementerian Kehutanan dan Kantor Pengurus Pembinaan Kesejahteraan Keluarga (PKK) serta di Fakultas Farmasi Universitas Gadjah Mada (UGM), Yogyakarta sebagai institusi yang banyak melakukan penelitian mengenai TO.

Informan pada penelitian ini pada tingkat pusat yaitu para pemegang kebijakan yang memiliki tugas dan fungsi mendorong, membuat program dan melakukan evaluasi terhadap kebijakan TO pada Direktorat Pelayanan Kesehatan Tradisional Kementerian Kesehatan (1 orang), Direktorat Sayuran dan Tanaman Obat Kementerian Pertanian (1 orang), dan Direktorat Jenderal Bina Usaha Kehutanan Kementerian Kehutanan (1 orang). Disamping itu informan juga meliputi pengurus PKK pusat (3 orang).

Informan pada tingkat daerah (kabupaten) yaitu para pemegang program yang memiliki tugas dan fungsi terkait program TO, yaitu dari Dinas Kesehatan, Dinas Pertanian dan Kehutanan, pengurus PKK, Badan Perencanaan Pembangunan Daerah (Bapeda), Badan Pemberdayaan
Masyarakat dan Desa (di Kabupaten Bogor), serta Bidang Kesejahteraan Rakyat Pemerintah Daerah Kabupaten Karanganyar. Jumlah peserta diskusi kelompok terarah untuk Kabupaten Bogor dan Kabupaten Karanganyar masing-masing sebanyak 10 orang (tidak termasuk peneliti). Informan akademisi/peneliti yaitu pakar TO dari Fakultas Farmasi UGM (1 orang), Balai Penelitian Tanaman Obat dan Rempah (Balittro) (2 orang), dan Balai Besar Penelitian dan Pengembangan Tanaman Obat dan Obat Tradisional Tawangmangu (B2P2TOOTT) (1 orang).

Selain itu, dilakukan juga pengumpulan dokumen-dokumen kebijakan dan hasil penelitian terkait kebijakan TO di institusi pemerintah pusat dan daerah, balai penelitian, dan universitas yang disurvei sebagai bahan kajian pustaka.

Data kualitatif, hasil transkrip wawancara mendalam, dan Kelompok Diskusi Terarah (KDT) dianalisis secara triangulasi serta didiskusikan secara intensif di dalam tim dan bersama dengan pakar. Untuk kemudian dipindahkan ke dalam matriks secara tematik. Dilakukan kajian terhadap dokumen kebijakan dan hasil penelitian yang berhasil dikumpulkan. Analisis kebijakan dilakukan dengan melakukan penilaian antara kebijakan dengan pelaksanaan di lapangan dan dikaji terhadap dokumen dan kepustakaan yang tersedia. Studi ini memperoleh izin etik dari Komisi Etik Badan Litbang Kesehatan, Kementerian Kesehatan.

\section{HASIL}

Rangkuman hasil wawancara mendalam di tingkat pusat terhadap pemegang kebijakan di sektor kesehatan, pertanian dan kehutanan serta PKK dapat dilihat pada Tabel 1 di bawah ini:

Tabel 1. Hasil Wawancara Mendalam di Kementerian Kesehatan, Kementerian Pertanian, Kementerian Kehutanan, dan Pengurus Pusat PKK

\begin{tabular}{|c|c|}
\hline \\
\hline \multicolumn{2}{|l|}{$\frac{\text { Kebijakan/Regulasi TO }}{\text { Kesehatan }}$} \\
\hline $\begin{array}{l}\text { Kebijakan lebih ke promotif dan } \\
\text { preventif untuk meningkatkan } \\
\text { status kesehatan dengan dasar } \\
\text { SK Nomor 381/Menkes/SK/ } \\
\text { III/2007 tentang Kebijakan Obat } \\
\text { Tradisional Nasional }\end{array}$ & $\begin{array}{l}\text { Orientasi pada skala industri } \\
\text { seperti perusahan-perusahan far- } \\
\text { masi yang memproduksi obat } \\
\text { tradisional. Untuk itu produk } \\
\text { TO harus berkualitas dan sesuai } \\
\text { dengan persyaratan, hal ini juga } \\
\text { sejalan dengan }\end{array}$ \\
\hline $\begin{array}{l}\text { Kebijakan integrasi TO untuk } \\
\text { masuk ke puskesmas dan rumah } \\
\text { sakit dengan melalui saintifikasi }\end{array}$ & $\begin{array}{l}\text { Peraturan Menteri Pertanian } \\
\text { No. 57/Permentan/OT.140/2012 } \\
\text { tentang }\end{array}$ \\
\hline jamu dengan dasar kebijakan & Pedoman Budidaya \\
\hline $\begin{array}{l}\text { Peraturan Menteri Kesehatan } \\
\text { Republik Indonesia }\end{array}$ & Obat yang Baik. \\
\hline $\begin{array}{l}\text { Nomor : 003/Menkes/Per/I/2010 } \\
\text { Tentang }\end{array}$ & $\begin{array}{l}\text { Peta jalan Roadmap Pengem- } \\
\text { bangan Jamu 2011-2025 dari }\end{array}$ \\
\hline $\begin{array}{l}\text { Saintifikasi Jamu dalam Peneli- } \\
\text { tian Berbasis }\end{array}$ & $\begin{array}{l}\text { Kementerian Koordinator } \mathrm{Bi}- \\
\text { dang Perekonomian, tetapi antara }\end{array}$ \\
\hline Pelayanan Kesehatan & $\begin{array}{l}\text { kebijakan dan implementasinya } \\
\text { belum sejalan }\end{array}$ \\
\hline
\end{tabular}




\begin{tabular}{|c|c|c|c|}
\hline \multicolumn{4}{|l|}{ Pengembangan TO } \\
\hline \multirow[t]{3}{*}{$\begin{array}{l}\text { Pengembangan TO sebagai self } \\
\text { care dan untuk dibudidayakan }\end{array}$} & $\begin{array}{l}\text { Pengembangan TO masih } \\
\text { terbatas hanya untuk } 6 \text { jenis } \\
\text { komoditas: temulawak, jahe, } \\
\text { kencur, kunyit, lidah buaya, } \\
\text { kapulaga, karena saat ini prioritas } \\
\text { utama Kementan masih pangan. }\end{array}$ & $\begin{array}{l}\text { Strateginya dengan konsep sen- } \\
\text { tra, yang sedang dikembangkan. } \\
\text { Tujuan sentra untuk efisiensi usa- } \\
\text { ha, mirip dengan koperasi. }\end{array}$ & $\begin{array}{l}\text { PKK ingin menyaring TO yang } \\
\text { khas dari setiap daerah melalui } \\
\text { program TOGA. Terdapat TOGA } \\
\text { yang bagus di Mojokerto dan } \\
\text { ada dukungan dari Bupati ke } \\
\text { masyarakatnya sehingga jadi } \\
\text { wisata TOGA. }\end{array}$ \\
\hline & $\begin{array}{l}\text { Kementan berusaha memper- } \\
\text { temukan industri dengan petani. } \\
\text { Kementan juga melatih/membina } \\
\text { petani dan masih terbatas pada } 6 \\
\text { komoditas }\end{array}$ & $\begin{array}{l}\text { Kegiatan terkait TO melakukan } \\
\text { temu usaha antara petani dan } \\
\text { pelaku usaha, contoh mempro- } \\
\text { mosikan kapulaga petani Jateng } \\
\text { dan Jabar. Di Jatim sedang } \\
\text { dikembangkan jahe, dan em- } \\
\text { pon-empon }\end{array}$ & $\begin{array}{l}\text { Di Barito Selatan (Kalimantan } \\
\text { Selatan) terdapat TOGA yang } \\
\text { bagus sekali dan TO sudah } \\
\text { ditanam di pinggir jalan. } \\
\text { Sekarang masyarakatnya bila } \\
\text { sakit mengambil dari situ. Ada } \\
\text { motivator bapak Alun Daya } \\
\text { (orang Dayak). Sehingga ada } \\
\text { tokoh yang mau memberitahu } \\
\text { masyarakat dan menggerakkan } \\
\text { masyarakat untuk menanam } \\
\text { TOGA. }\end{array}$ \\
\hline & & & $\begin{array}{l}\text { Pemerintah harusnya jangan } \\
\text { hanya memberikan benih tapi } \\
\text { juga melakukan pembinaan. }\end{array}$ \\
\hline
\end{tabular}

\footnotetext{
Program terkait TO promosi. lahan dan pemanfaatan TOGA

Pelatihan TO dengan peserta tenaga kesehatan dan dokter dari seluruh provinsi dan setiap provinsi yang mengikuti 2 orang. Harapannya dari provinsi akan turun ke kabupaten sehingga masyarakat memanfaatkan TO serta membina kader posyandu
}

Membuat TOGA di desa dan Pekan Flori-Flora, ajang promo- Programnya mengupayakan ber- Lomba TOGA dalam rangka

di kantor kesehatan/puskesmas si dan ajang komunikasi di taraf dirinya sentra termasuk sentra pemberdayaan dan untuk

sebagai percontohan dan media internasional. Ini merupakan TO sebanyak 6 sentra per tahun pemanfaatan - TO

agenda tahunan. Tahun 2013 kerja sama dengan Kelompok Kerja

Membuat buku pedoman pengo- Nasional Tanaman Obat Indonesia (POKJANAS TOI). Ada pam- $\begin{array}{lrr}\text { pemanfaatan } & \text { TO } & \text { oleh } \\ \text { masyarakat. } & \text { Lomba } & \text { TOGA }\end{array}$ mulai 2009, awalnya tidak dengan Kemenkes. Hampir seluruh provinsi ikut. Salah satu kriteria pemenang TOGA adalah dalam 1 kelurahan berapa jumlah rumah yang memiliki TO dan memanfaatkannya untuk keluarga, setelah berlebih baru dijual.

\section{Permasalahan}

Kalangan profesional kedokteran Harapan ada kebijakan yang Masalah klasik: petani tidak Hampir tidak ada masalah. Hanya banyak yang masih belum mener- menyambungkan karena berbeda punya pembeli sementara pelaku mungkin karena kesibukan ima pengobatan dengan TO prioritas antara sektor pertanian industri tidak punya barang, tapi dan kesehatan. Di pertanian TO tidak bertemu

Harga TO rendah sehingga petani merupakan komoditas dengan enggan menanam prioritas paling bawah, akan diupayakan supaya TO diangkat supaya ada semangat untuk memajukan TO.

Dari kesehatan supaya proaktif, "ajak lah dinas-dinas untuk mengembangkan TOGA". Supaya bottom up. Dari tingkat atas (pusat) hanya membuat road map. kementerian belum sepenuhnya menangani.

PKK bergerak terlalu cepat, sementara pemerintah masih kurang jalan. PKK belum tahu untuk masalah TO hubungannya harus kemana?

Harapannya kementerian bisa lebih intens lagi dengan TOGA. Puskesmas supaya merangkul PKK dan masyarakat. Jangan merasa PKK mengerjakan program pemerintah karena banyak kader PKK yang bergerak.

"Kami melakukan lomba TOGA punya dasar yaitu Dasawisma" yang meliputi penggerakan dan pembinaan masyarakat serta pencatatan hasil dan informasi dari aktivitas di lapangan. 


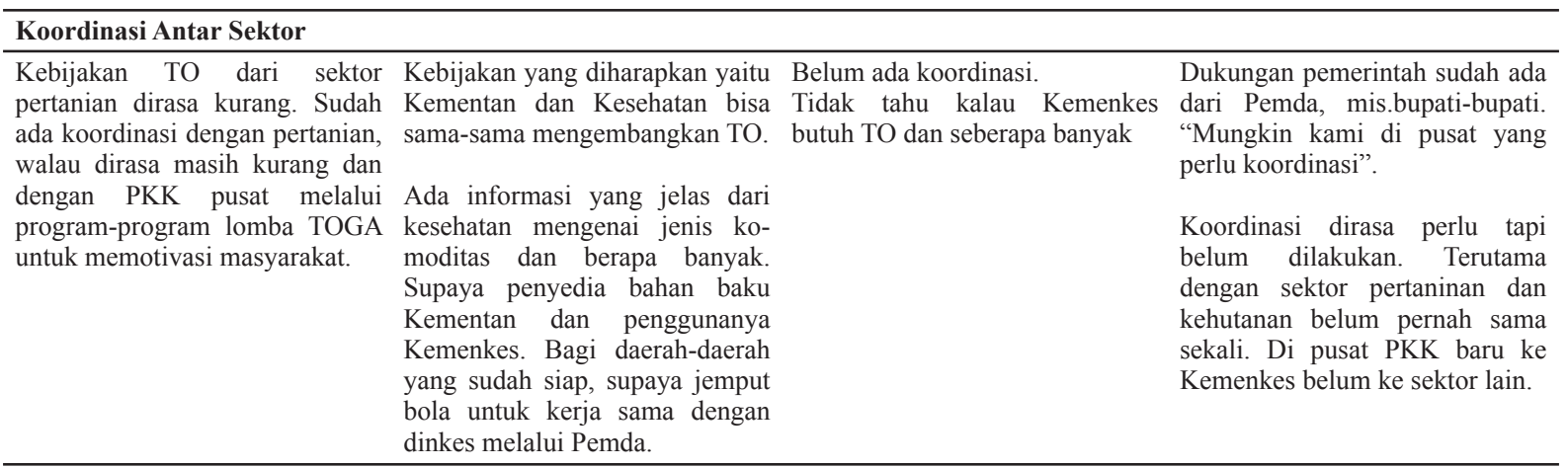

Hasil KDT antar institusi di tingkat kabupaten menunjukkan bahwa program TOGA telah berjalan di kedua kabupaten (Bogor dan Karanganyar). Pengurus PKK di kabupaten Bogor menyatakan bahwa mereka menganggarkan TOGA untuk setiap desa sebesar Rp.5.000.000.00 per desa per tahun, dan rencananya setiap tahun akan tetap dialokasikan anggaran untuk TOGA. Sementara itu informan dari Dinas Kesehatan mengatakan bahwa TOGA merupakan salah satu kriteria desa siaga. Tetapi dinyatakan juga bahwa sosialisasi TOGA dilakukan hanya pada saat akan ada lomba TOGA dan bersifat parsial (hanya untuk sekolah yang akan ikut lomba). Disamping itu boleh dikatakan juga bahwa tidak ada dukungan dana untuk TO dari pusat, hal berikut disampaikan oleh informan dari Dinas Kesehatan:

“... dari pusat tidak ada kecuali hanya pada waktu mau membuat buku TO kabupaten diikutkan".

Pusat diharapkan dapat membantu untuk penyediaan buku pintar/leaflet/brosur mengenai TO yang dirasa masih sangat kurang yang diperlukan untuk meningkatkan pemahaman terhadap jenis TO dan khasiatnya.

Untuk Kabupaten Karanganyar di Jawa Tengah telah dikembangkan program saintifikasi jamu yang merupakan uji coba untuk memasukkan jamu ke dalam fasilitas kesehatan formal. ${ }^{14}$ Tetapi program ini masih memiliki beberapa kendala yaitu biaya pengobatan dengan jamu masih dibebankan pada masyarakat, sehingga resep dengan ramuan jamu lebih mahal dari resep obatobat umum. Obat-obat umum diberikan dalam satu paket pelayanan dengan karcis pelayanan puskesmas (pasien tidak perlu membayar), tetapi untuk resep obat tradisional pasien diharuskan membayar lagi.

Informasi yang didapat dari KDT di kabupaten Bogor bahwa pertanian dan kehutanan berada dalam satu dinas dan dinas ini pernah membuat UPT pengembangan TO tahun 2005 yang terdiri dari Pemda, Badan Pengkajian dan Penerapan Teknologi, dan PT. ANTAM dimana PT. ANTAM sebagai penyedia sarana dan prasarana kebun plasma untuk diteruskan kepada kelompok tani. Tapi kegiatan tersebut berhenti pada tahun 2010, dan tahun 2013 lahan tersebut mulai diperbaiki lagi.

Belum adanya jaminan pasca panen menjadi masalah lain yang dikeluhkan oleh sektor pertanian dan kehutanan. Di kabupaten Karanganyar Jawa Tengah telah dikembangkan kemitraan sistem klaster dengan petani untuk pemberdayaan masyarakat sehingga petani mulai menanam TO ${ }^{15}$ Informan KDT dari Dinas Pertanian Karanganyar mengatakan:

"Petani sudah senang menanam TO tetapi karena mutunya kurang bagus hasil panennya ditolak, sehingga motivasi petani menurun."

Hal lain yang dikeluhkan semua sektor adalah rendahnya harga bahan baku obat, misal untuk rimpang menanamnya lama tapi harga jualnya murah. ${ }^{16}$

\section{PEMBAHASAN}

Berdasarkan wawancara mendalam dengan pemegang kebijakan di tingkat pusat, yaitu di Kementerian Kesehatan, Pertanian dan Kehutanan diperoleh informasi bahwa sudah ada regulasi mengenai TO, walaupun belum sepenuhnya didukung oleh program rutin. Hal ini berimbas terhadap program dan anggaran untuk pengembangan TO yang masih sangat 
kurang. Pada sektor pertanian TO diprogramkan hanya untuk enam jenis, yaitu jahe, kunyit, kapulaga, temulawak, lidah buaya, dan kencur. Senada dengan itu pakar TO di sektor pertanian mengatakan bahwa saat ini hanya fokus untuk TO yang diminati industri dan yang sudah banyak dikenal manfaatnya oleh masyarakat seperti kumis kucing, sambiloto, dan lain-lain. Situasi yang sama juga merupakan gambaran hasil penelitian yang dari Lembaga Penelitian dan Pengembangan (Litbang) Kementerian Pertanian. ${ }^{17}$

Selain lembaga resmi pemerintahan, upaya pengembangan TO juga sudah dikembangkan oleh sektor informal seperti PKK, yang bahkan telah memiliki program rutin melalui lomba TO keluarga (TOGA) yang dilakukan secara rutin setiap tahun. Untuk membantu pemasaran TO, Kementerian Kehutanan menerapkan konsep sentra. Manajemen dan operasional sentra mirip dengan koperasi. Tujuan sentra selain untuk pemasaran juga untuk efisiensi usaha. Kementerian Pertanian membuat "Pekan Flori-Flora", ajang promosi dan ajang komunikasi di taraf internasional. Ini merupakan agenda tahunan dan salah satu kegiatan adalah pameran TOGA.

Terdapat juga Kelompok Kerja Nasional Tumbuhan Obat Indonesia (POKJANAS TOI) yang anggotanya berasal dari institusi lintas sektor yaitu institusi pemerintah, swasta, dan universitas dengan sekretariat di Kementerian Kesehatan yang bertujuan "mengkoordinasi penelitian dan pengembangan di bidang tumbuhan obat termasuk obat tradisional Indonesia, yang mencakup pelestarian dan budidaya tumbuhan obat (dalam hal ini lebih ditekankan pada jamu), pascapanen, fitokimia, khasiat dan keamanan, teknologi farmasi, pemasaran, pengaturan, pengembangan database dan pengendalian mutu. Kedepannya POKJANAS ini diharapkan bisa lebih mendorong pencapaian pemanfaatan TO untuk skala yang lebih luas. ${ }^{18}$

Orientasi TO pada sektor kesehatan dan PKK adalah untuk menyembuhkan dan menyehatkan diri sendiri, baru kemudian untuk dibisniskan. Walau pada sektor kesehatan TO merupakan prioritas, tetapi pada kenyataannya belum didukung anggaran yang memadai yang dapat mendorong pengembangan TO menjadi lebih baik. Pada tahun 2011 mulai dibentuk direktorat "Pelayanan Kesehatan Traditional" di Kementerian Kesehatan sehingga TO sudah mulai mendapat porsi program yang lebih dari sebelumnya. Pilot project saintifikasi jamu merupakan suatu langkah terobosan dari Kementerian Kesehatan agar obat tradisional dapat diintegrasikan dalam pelayanan kesehatan formal. ${ }^{19}$ Saintifikasi Jamu merupakan upaya dan proses pembuktian ilmiah jamu melalui penelitian berbasis pelayanan kesehatan yang bertujuan untuk memberikan landasan ilmiah (evidence based) penggunaan jamu secara empiris melalui penelitian berbasis pelayanan kesehatan. Untuk kemudian dapat dintegrasikan kedalam pelayanan kesehatan formal. Upaya integrasi tersebut sudah dilaksanakan di beberapa puskesmas di Kabupaten Karanganyar Jawa Tengah. Akan tetapi program ini masih menghadapi banyak kendala, yaitu terbatasnya supply bahan baku jamu untuk pelayanan jamu di puskesmas serta belum ada peraturan daerah yang mengatur biaya pengobatan dengan jamu bisa masuk ke biaya puskesmas seperti resep umum, dan akibatnya pasien membayar lebih mahal untuk resep jamu dari pada resep umum. ${ }^{20,12}$ Puskesmas di Kabupaten Karanganyar menerima racikan jamu dari B2P2TOOTT Tawamangu, contohnya racikan jamu untuk penderita hipertensi dan racikan jamu untuk penderita diabetes. Sebaiknya puskesmas yang memberikan pelayanan jamu diberi kewenangan untuk meracik sendiri karena setiap puskesmas sudah punya apoteker masingmasing dan apoteker ini dapat dilatih.

Di era Jaminan Kesehatan Nasional (JKN) ini, untuk mengintegrasikan jamu kedalam pelayanan fasilitas kesehatan formal maka jamu harus bisa masuk kedalam Formularium Nasional (Fornas). Obat-obat yang masuk kedalam Fornas adalah obat yang sudah memiliki hasil uji klinis termasuk hasil uji toksikologi dan terdaftar di Badan Pengawasan Obat dan Makanan (BPOM) sebagai obat. Sementara itu pada umumnya jamu tidak memiliki hasil uji klinis dan terdaftar sebagai di BPOM sebagai obat tradisional. Oleh karena itu, agar jamu dapat masuk kedalam Fornas maka perlu pengembangan jamu ke arah fitofarmaka atau terstandar atau dengan adanya 
terobosan kebijakan sendiri sehingga pengobatan jamu dapat dibiayai oleh program JKN. ${ }^{21,22}$ Dapat dikatakan bahwa kebijakan saintifikasi jamu belum dapat menjawab permasalahan di lapangan, sehingga tujuan untuk mengintegrasikan jamu ke dalam pelayanan kesehatan formal masih cukup sulit terlaksana.

Hasil diskusi KDT mengindikasikan bahwa peserta merasa bahwa masih kurangnya keberpihakan untukTO. Permasalahan hasil panen yang mutunya kurang bagus sehingga tidak dapat digunakan sebagai bahan baku TO melemahkan motivasi petani untuk menanam TO. Situasi ini terjadi mungkin karena kurangnya pemahaman petani terhadap cara budidaya TO yang baik. Hasil penelitian yang ada menyatakan bahwa upaya pengembangan TO menghadapi masalah kurangnya informasi tentang penggunaan benih bermutu sehingga masih banyak petani yang menggunakan benih asalan yang tidak terjamin mutunya yang berdampak produktivitas dan kualitas produk yang dihasilkan masih rendah. ${ }^{23}$ TO yang dapat digunakan sebagai bahan baku jamu untuk saintifikasi jamu haruslah memenuhi beberapa persayaratan seperti kadar kandungan aktif, kadar air, dan kadar cemaran pada batas yang masih dapat ditoleransi yang sesuai Farmakope Herbal Indonesia atau gold standard yang ada. Agar TO hasil panen petani dapat diterima maka Kementerian dan Dinas Pertanian perlu memberikan bimbingan teknis dan dorongan agar petani tetap bersemangat untuk menanam TO. Sehingga hasil panen TO oleh petani memiliki mutu yang sesuai untuk dijadikan OT yang dapat berimbas terhadap harga jual TO yang lebih baik. Dari interaksi peserta KDT dan hasil diskusi dapat dikatakan bahwa koordinasi lintas sektor di kedua kabupaten sudah cukup baik. Di lain pihak, secara umum dapat dikatakan koordinasi lintas sektor di pusat masih belum optimal. Koordinasi antar kesehatan dan pertanian sudah terjalin tetapi dengan kehutanan masih kurang. Sektor pertanian dan kehutanan membutuhkan informasi dari sektor kesehatan yaitu jenis apa saja dan seberapa banyak TO yang dibutuhkan oleh sektor kesehatan. Demikian pula koordinasi antar sektor kesehatan dengan PKK pusat masih kurang, masih terbatas pada penyelenggaraan lomba TOGA nasional. Koordinasi PKK dengan sektor lainnya belum terjalin baik.

Koordinasi dari pusat ke daerah juga belum optimal. Di era otonomi daerah prioritas kesehatan sangat tergantung dari political will kepala daerah. Ada daerah yang menunggu agar pusat memberikan program-program dan pedoman TO ke daerah, tetapi ada juga yang mulai dari bupati aktif untuk mengembangkan TO. Pengurus PKK pusat meyebutkan:

"Terdapat TOGA yang bagus di Mojokerto dan ada dukungan dari bupati ke masyarakatnya sehingga jadi wisata TOGA"

Hal yang perlu mendapat perhatian juga adalah jangan sampai TO di Indonesia jadi berkurang karena illegal lodging, deforestry, dan pembalakan liar untuk TO yang sedang naik daun. Jadi selain eksplorasi TO yang belum dikenal, pelestarian TO juga perlu dilakukan. ${ }^{20}$

Pakar TO UGM merekomendasikan untuk memenuhi kebutuhan bahan baku TO industri dan saintifikasi jamu, serta sebaiknya TOGA dikaitkan dengan upaya memenuhi kebutuhan bahan baku bukan hanya untuk lomba. TOGA pada pekarangan rumah tangga harus bisa menjadi penyangga penyediaan bahan baku obat. ${ }^{15,24}$ Sehinga TO tidak harus dibudidayakan di sawah/ladang sehingga petani tetap dapat menanam padi atau lainnya. Tetapi gerakan ini harus menjadi gerakan nasional yang dipayungi oleh suatu kebijakan formal. Sebaiknya memberdayakan PKK untuk mendorong ibuibu rumah tangga agar termotivasi membuat TOGA di pekarangannya agar dapat digunakan sendiri tapi sekaligus juga sebagai penyedia bahan baku. Dengan kata lain, apabila dilakukan pembinaan mengenai budidaya TO yang baik dan benar beserta manfaatnya seharusnya TO yang ditanam di rumah tangga dapat dikumpulkan dan diolah menjadi obat herbal sehingga akan meningkatkan nilai jualnya. Dengan demikian, kegiatan pertanian tersebut dapat menjadi sumber tambahan penghasilan dan kesempatan kerja bagi masyarakat sehingga dapat menjadi penyangga kestabilan ekonomi. ${ }^{24}$

Pakar dari balai penelitian sektor pertanian mengingatkan bahwa untuk memiliki nilai tambah harus ada upaya untuk menjadikan TO menjadi fitofarmaka :

"Jangan berhenti pada jamu yang 


\section{uangnya banyak"}

Pemerintah perlu mendorong masyarakat dan industri untuk pengembangan TO menjadi fitofarmaka dan obat tradisional terstandar. Untuk itu perlu ada konsep dan prioritas dari pemerintah, TO apa yang akan didorong ke arah fitofarmaka. Saat ini obat fitofarmaka yang sudah terdaftar di BPOM masih terbatas dan merupakan hasil penelitian dari individu peneliti/ industri, bukan merupakan program pemerintah. Bila pemerintah dan masyarakat/swasta bekerja sama untuk mendorong produk fitofarmaka dan pemanfaatannya, maka TO memiliki nilai tambah dan lebih mudah dintegrasikan kedalam Fornas untuk program JKN.

Agar TO dapat menjadi komoditi yang diandalkan untuk menunjang kesehatan dan ekonomi masyarakat masih memerlukan jalan panjang. Untuk itu, TO di Indonesia perlu secara terus menerus didorong pengembangannya dengan melibatkan kerjasama lintas sektor serta masyarakat luas dengan didukung program yang jelas dan berkesinambungan. ${ }^{25,26,27}$ Kebijakan yang sudah ada di masing-masing sektor harus dapat diwujudkan secara terarah, antara lain budi daya TO, standarisasi, penelitian dan pengembangan, pembinaan industri obat herbal, jaminan mutu dan keamanan, pengembangan pasar domestik dan ekspor serta terintegrasinya penggunaan obat herbal dalam pelayanan kesehatan forma. ${ }^{21}$ Kebijakan terobosan diperlukan untuk percepatan TO agar TO dapat menjadi tuan rumah di Indonesia seperti batik yang sudah "go global" sebagai hasil produk Indonesia.

\section{KESIMPULAN}

Masih terdapat gap antara kebijakan TO dengan pelaksanaan di lapangan, sehingga program pengembangan TO belum optimal. Kebijakan Obat Tradisional Nasional masih kurang diimplementasikan ke dalam program yang memiliki daya ungkit terhadap pengembangan TO. Saintifikasi jamu juga masih menghadapi beberapa masalah di lapangan yang harus segera diselesaikan.

Pada tingkat pusat terlihat bahwa TO ada di masing-masing sektor, hanya prioritasnya yang berbeda-beda. Kebijakan di sektor kesehatan lebih mengarah kepada bagaimana pengobatan dengan TO bisa berintegrasi dengan pelayanan kesehatan formal dan swamedikasi, sementara sektor pertanian dan kehutanan mengarah kepada industrialisasi untuk meningkatkan taraf ekonomi masyarakat.

Pada tingkat daerah, pengembangan TO masih mengharapkan dukungan dari pusat terutama untuk anggaran dan pembinaan. Pembinaan yang diharapkan dari sektor kesehatan adalah pedoman tentang manfaat TO dan aturan pakai yang benar, dari pertanian terkait budidaya TO agar hasil yang diperoleh berkualitas sehingga harga TO dapat baik, serta memiliki pangsa pasar yang stabil. Hasil analisis pakar menunjukkan pengembangan TO masih perlu ditingkatkan.

\section{SARAN}

Secara umum, masalah koordinasi masih menjadi kelemahan setiap sektor, baik koordinasi lintas sektor maupun koordinasi dari pusat ke daerah. Program-program yang sudah baik di tingkat pusat menjadi kurang berarti karena kurangnya sosialisasi dan pelaksanaan di lapangan, khususnya di daerah. Untuk itu forum-forum seperti forum Pokjanas TOI dan forum-forum sejenisnya masih dibutuhkan, terutama tindak lanjut pada waktu implementasi di lapangan. Dan diperlukan adanya kebijakan terobosan untuk peningkatan pemanfaatan TO baik untuk kesehatan maupun peningkatan ekonomi.

\section{UCAPAN TERIMA KASIH}

Terima kasih kepada seluruh pihak yang telah membantu untuk memberikan informasi terhadap studi ini baik dari sektor kesehatan, pertanian, kehutanan, balai penelitian tanaman obat dan UGM (Prof. Dr. Suwijiyo Pramono) serta pihak lain terkait yang tidak dapat kami sebutkan satu persatu. Terima kasih secara khusus disampaikan kepada Riswati, S.Si. dari Puslitbang Humaniora dan Manajemen Kesehatan Badan Litbangkes yang ikut langsung membantu jalannya penelitian ini.

\section{DAFTAR PUSTAKA}

1. WHO. WHO traditional medicine strategy: 2014-2023. Geneva: World Health Organization; 2015.

2. Robinson MM,Zhang X. The world medicines situation 2011 traditional medicines : global 
situation, issues and challenges. In: World Health Organization. 3 rd. Geneva: World Health Organization; 2011.

3. Ekor M. The growing use of herbal medicines: issues relating to adverse reactions and challenges in monitoring safety. Front Pharmacol. 2014 Jan 10;4:177.

4. Departemen Kesehatan Republik Indonesia. Kebijakan Obat Tradisional Nasional Tahun 2007. Jakarta: Departemen Kesehatan Republik Indonesia; 2007.

5. Komala L, Hafiar H, Subekti P. Jejaring komunikasi dalam penyebaran informasi obat herbal di kalangan pengguna. J Ilmu Komun. 2016 Apr 15;3(1):85-94.

6. Helmi A. Persepsi dan perilaku masyarakat terhadap obat herbal. J Ekon dan Bisnis Terap. 2017 May 6;13(2).

7. Supardi S, Herman MJ, Yuniar Y. Penggunaan Jamu buatan sendiri di Indonesia (analisis data riset kesehatan dasar tahun 2010). Bul Penelit Sist Kesehat. 2011;14(4):375-81.

8. Badan POM RI. Standardidasi ekstrak tumbuhan obat indonesia, salah satu tahapan penting dalam pengembangan obat asli Indonesia. Info POM. 2005;6(4).

9. Hakim I. Kajian kelembagaan dan kebijakan hutan tanaman rakyat: sebuah terobosan dalam menata kembali konsep pengelolaan hutan lestari. J Anal Kebijak Kehutan. 2009;6(1).

10. Hermawan I. Daya saing rempah Indonesia di pasar asean periode pra dan pasca krisis ekonomi global. Bul Ilm Litbang Perdagang. 2015 May;9(2):153-78.

11. Dewoto HR. Pengembangan obat tradisional Indonesia menjadi fitofarmaka. Maj Kedokt Indones. 2007;57(7):205-11.

12. Purwaningsih EH. Jamu, obat tradisional asli Indonesia pasang surut pemanfaatannya di Indonesia. eJournal Kedokt Indones. 2013;1(2).

13. Mayrowani H, Ashari. Pengembangan agroforestry untuk mendukung ketahanan pangan dan pemberdayaan petani sekitar hutan. Forum Penelit Agro Ekon. 2011 Aug 11;29(2):83-98.

14. Delima D, Widowati L, Astuti Y, Siswoyo H, Gitawati R PA. Gambaran praktik penggunaan jamu oleh dokter di enam provinsi di Indonesia. Bul Penelit Kesehat. 2012;40(3).

15. Sundawati L, Purnaningsih N, Purwakusumah ED. Pengembangan model kemitraan dan pemasaran terpadu biofarmaka dalam rangka pemberdayaan masyarakat sekitar hutan di Kabupaten Sukabumi, Provinsi Jawa Barat. J Ilmu Pertan Indones. 2012 Aug $23 ; 17(3): 153-8$.

16. Toga NR, Fahma F, Budijanto M. Penentuan harga pokok produksi kunyit dan produk olahan di klaster biofarmaka Kabupaten Karanganyar. PERFORMA. 2013;12(1).

17. Pribadi ER. Pasokan dan permintaan tanaman obat Indonesia serta arah penelitian dan pengembangannya. Perspektif. 2009;8(1):52-64.

18. Balai Besar Penelitian dan Pengembangan Tanaman Obat dan Obat Tradisional Balitbangkes Kemenkes. POKJANAS TOI Available from:http://www.b2p2toot.litbang. kemkes.go.id/?page $=$ postcont $\&$ postid $=66 \&$ content $=$ Pokjanas + TOI

19. Widowati L, Siswanto S, Delima D, Siswoyo H. Evaluasi praktik dokter yang meresepkan jamu untuk pasien penderita penyakit degenerative di 12 propinsi. Media Penelit dan Pengemb Kesehat. 2014 Oct $23 ; 24(2): 95-102$.

20. Suyodono I, Syaufina L, Suharjito D. Analisis pola kemitraan agroforestri dalam rangka mengurangi ancaman perambahan hutan (studi kasus tumpangsari tanaman pangan di IUPHHK-HT Pulau Laut Kotabaru Kalimantan Selatan. J Pengelolaan Sumberd Alam dan Lingkung 2014 Jul 31;4(1):1.

21. Sriatmi A, Jati SP, Rahmawati A. Analisis implementasi pengintegrasian pelayanan kesehatan tradisional di puskesmas Halmahera Kota Semarang. J Kesehat Masy Univ Diponegoro. 2016 Mar 2;4(1).

22. Artana W. Analisis Fungsional terapi tradisional dan terapi komplementer alternatif diera jaminan kesehatan nasional (Jkn). J Publ Penelit Kebidanan dan Keperawatan. 2017 Jun 19;1(1).

23. Sujianto S, Wahyudi A. Analisis kelayakan dan finansial dalam penyediaan benih bermutu jahe merah (Zingiber officinale var. rubrum). Bul Penelit Tanam Rempah dan Obat. 2016;26(1):77-86.

24. Listya D. Kajian peran pertanian perkotaan dalam pembangunan perkotaan berkelanjutan (studi kasus: pertanian tanaman obat keluarga di Kelurahan Slipi, Jakarta Barat). Forum Ilm. 2014;11(3).

25. Towe VL, Leviton L, Chandra A, Sloan JC, Tait M, Orleans T. Cross-Sector collaborations 
and partnerships: essential ingredients to help shape health and well-being. Health Aff (Millwood). 2016 Nov 1;35(11):1964-9.

26. Diana Sari I, Yuniar Y, Siahaan S, Syaripuddin M. Tradisi masyarakat dalam penanaman dan pemanfaatan tumbuhan obat lekat di pekarangan. J Kefarmasian Indones. 2015;5(2):123-32.
27. Murni S A, Prawito P WS. Eksistensi pemanfaatan tanaman obat tradisional (TOT) Suku Serawai di era medikalisasi kehidupan. Jurnal Penelitian Pengelolaan Sumber Daya Alam dan Lingkungan. 2012;1(3). 